\title{
Analysis of wheel/rail interaction for the development of a new tramway wheel profile
}

\author{
T. Staskiewicz \& B. Firlik \\ Department of Rail Vehicles, Poznan University of Technology, Poland
}

\begin{abstract}
The paper presents results of multi-body simulation analysis of the influence of wheel profile geometry on vehicle's dynamic response and finite element method analysis of contact stress in wheel material. Thermovision camera pictures of wheel/rail interface during regular operation were also captured.

Performed research indicates that the most important parameter influencing tramway dynamics, including ride safety, is wheel/rail clearance. The others are: radius of flange root and shape of the wheel tread. Moreover, providing singlepoint contact between wheel and rail contributes to decrease in wear and as a consequence, maintenance cost. Riding through rail crossings involves flange tips in formation of the contact with rails.

On the basis of the analysis carried out, tramway wheel profile optimization will be undertaken. The process will exploit genetic algorithm as well as finite element method and multi-body simulation software in automated loop to prepare a set of new wheel profiles and choose the ones with the best parameters for further examinations and then for supervised operation.

Keywords: wheel/rail interface, rail vehicle dynamics.
\end{abstract}

\section{Introduction}

The quality of interaction between wheel and rail has significant influence on ride safety, comfort, noise and vibration emission and wear intensity. By the ride safety it goes safety against derailment, which should be guaranteed on a high level. The ride comfort is essential for passengers and along with new vehicles coming into service it should increase. Finally, the intensity of wear is significant regarding the cost efficiency. Tramway wheel profiles in Poland are quite old, the newest dates back in the 1990s. Therefore, a complex analysis of phenomena at the wheel/rail 
contact area should be done as a groundwork for development of new tramway wheel profile.

The paper is focused on the interaction between tram wheel and rail, which was examined referring to thermovision video recordings, finite element method analysis and multi-body simulations.

\section{Methodology}

\subsection{Finite element method analysis}

The finite element method analysis was carried out in Abaqus software. Model consisted of a wheel rail pair. Two wheel profiles where examined, T and PST (Polish ones) and two types of rails, 60R2 and 49E1. Additionally, ride through rail crossing was investigated.

\subsection{Multi-body simulations}

Simulations of tramway dynamics were conducted using five-section, low-floor, articulated tramway vehicle model (passengers' load was included) in SIMPACK software. Selected European wheel profiles were investigated on track with measured geometry, originating from Poznan, Poland. List of analysed wheel profiles was shown in Table 1.

Table 1: List of investigated wheel profiles.

\begin{tabular}{|l|c|}
\hline Profile name & Origin \\
\hline T & Poland \\
PST & Poland \\
V15 & UK, Blackpool \\
FIAT & Italy \\
VM & Czech Republic, Prague \\
Zurich & Austria, Zurich \\
BOStrab A & Germany, Berlin \\
\hline
\end{tabular}

Simulation rides were carried out with the maximum permissible velocity of $30 \mathrm{kmph}$ established on the corresponding real track section. Two rail types were examined: 60R2 and 49E1. Following dynamic parameters were calculated: $Y / Q$ derailment coefficient, ride index, ride comfort and number of contact patches.

\section{Results}

\subsection{Formation of contact areas}

As stated in [1] single-point or multiple-point contacts may appear during exploitation. It was found that providing single-point contact improves riding performance and durability of wheels and rails [2,3]. Moreover, wear resistance 
may be increased by enlarging the contact area (introducing conformal shapes of wheel profiles and rails). This may also affect negatively ride stability due to raised conicity parameter [3], however regarding tramways' low cruising velocities it becomes negligible. Two-point contact is shown in Figure 1 (left). Pictures were taken from thermovision camera.

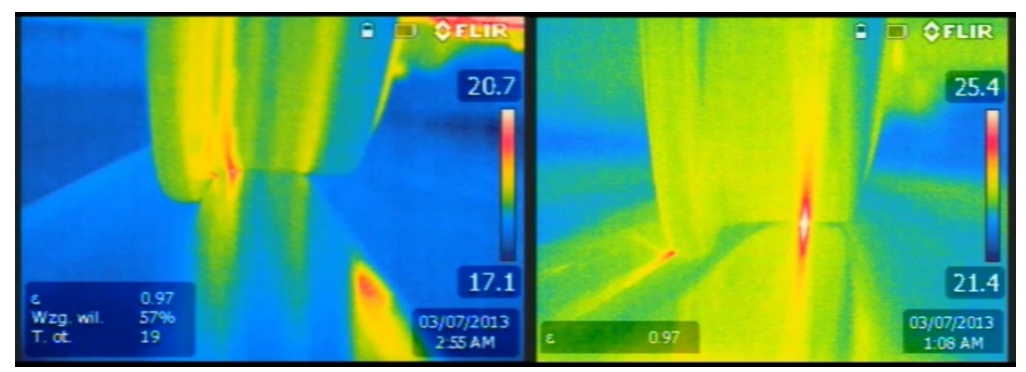

Figure 1: Contact locations: in curve (left), backflange (right).

The above figure shows transparently the locations of contact points (red, warmer regions). In general, multiple contact points are situated on different wheel diameters, thus their rolling velocities are various. It leads to occurrence of slippages between wheel and rail and in consequence to increased wear rate and noise pollution $[4,5]$. This situation may appear not only while negotiating track curves but also in a straight section due to bad technical condition of infrastructure and/or hunting movement of the vehicle [1]. Other contact areas may emerge on checkrail of the grooved rail (backflange contact), which is presented on Figure 1 (right part). It is tribologically adverse situation, but this type of contact was designed to increase safety against derailment in narrow curves, on bridges and in tunnels.

One of the biggest challenges which arise while considering tram wheel/rail interaction are rail crossings, especially the flat grooved ones, where the contact patch moves to the flange tip (Figure 2, left).

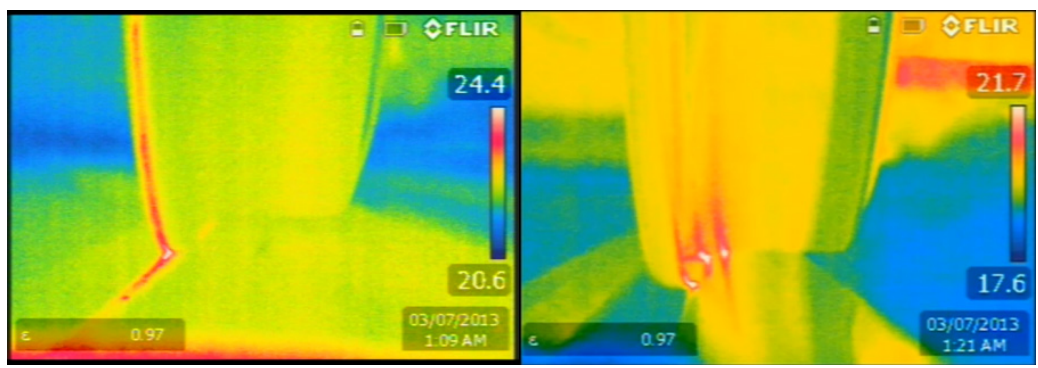

Figure 2: Contact locations: flat grooved rail crossing (left), curve (right).

Due to very small contact area the contact stress is very high, which leads to plastic deformations of wheels and rails. The ways to reduce the negative impact 
of rail crossings are among others: expansion of the contact area by redefining wheel profile, lowering the axle loads or replacing flat grooved rail crossings with deep grooved ones, which involve only wheel thread into contact. Since the idea of the project is to develop a new tramway wheel profile, authors focused on the influence of wheel profile geometry on vehicle's ride characteristics. Some brief reflections are included in the next section.

\subsection{Vehicle dynamics simulation}

Firstly, location of potential points of contact regarding lateral wheelset displacement $\pm 10 \mathrm{~mm}$ was investigated for profiles T and PST (Figure 3). Blue lines mean first (single) contact points, green line indicates occurrence of twopoint contact.
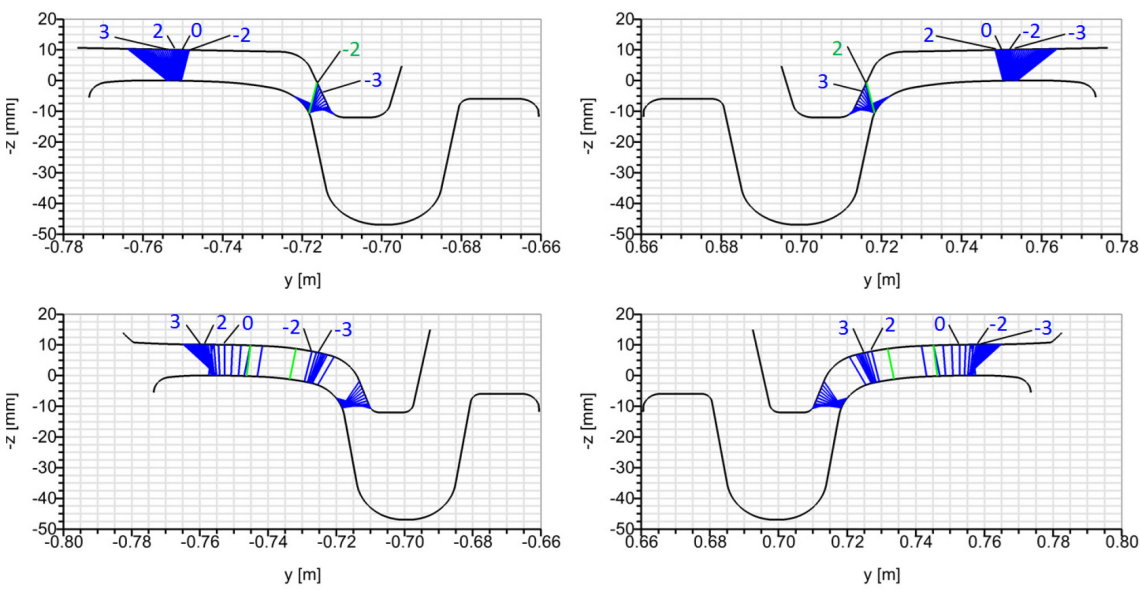

Figure 3: Potential points of contact on 60R2 rails (top: T, bottom: PST).

Single-point contact appeared in almost entire range of lateral displacements of $\mathrm{T}$ profile. Contact patch moved discontinuously from wheel tread to flange. It leads to momentary two-point contact and slippage due to difference in circumferential velocity of wheel (rolling radii difference) $[4,5]$. In range of wheelset's small, $\pm 2 \mathrm{~mm}$ lateral movements the contact point was performing a considerable jump between wheel tread and flange. It may cause accelerated wear [2]. Contact patches were very close to each other and covered a small area for $\mathrm{T}$ profile, which means higher ride stability which is of little importance for tramways since they rarely travel at top speed of $70 \mathrm{kmph}$. The conformity of wheel and rail shapes was low, it may effect in increase of contact stresses. Mostly single-point contacts between profile PST wheels and 60R2 rails are seen from above. Two-point contact appeared only temporarily and differences in rolling radii were not as large as in case of profile $T$, but still not without impact on vehicle dynamics. Contact patches were distributed over the width of wheel more uniformly, however there were still noticeable gaps between $\pm 2 \mathrm{~mm}$ contact 
patches. It should affect vehicle dynamics and wheel wear negatively [2]. The shapes of wheel and rail were conformal, thus contact stress should be low.

Different wheel profiles offer various ride characteristics [6]. One of the most important is $Y / Q$ derailment coefficient, which should be maintained as low as possible and not exceeding limiting value, which is calculated separately for particular wheel profiles (Nadal criterion) [7]. The following Figure 4 shows derailment coefficients during simulation rides on straight track section with measured rail irregularities.

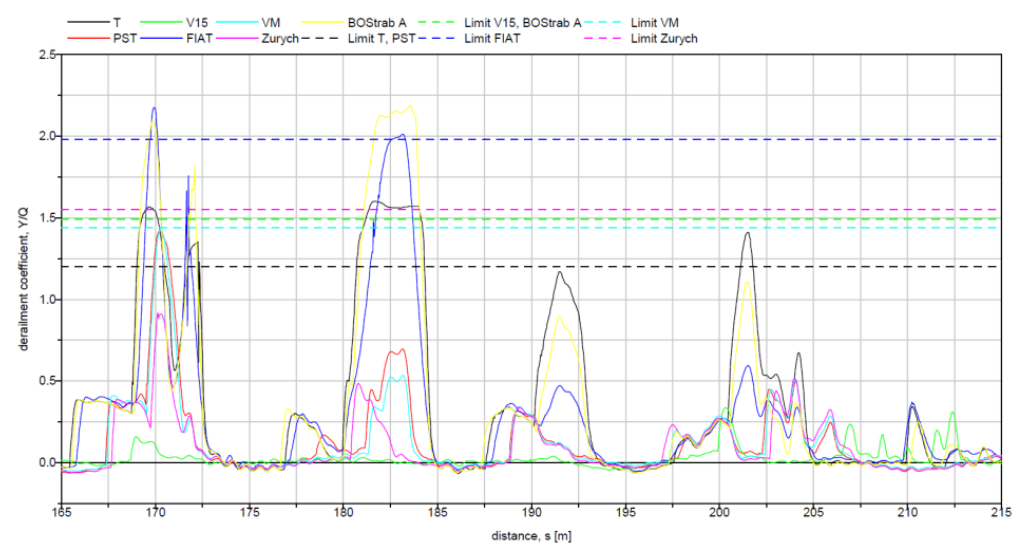

Figure 4: $\quad Y / Q$ coefficient for various wheel profiles (first wheelset, right wheel).

The above figure indicates that profiles T, FIAT and BOStrab A achieved the worst results. All of them transgressed respective limit values. The lowest values got profile V15. The differences in $Y / Q$ coefficient between specific wheel profiles were considerable. Every profile, which passed its limit value was climbing on rail.

Figure 5 presents maximum values of ride index in lateral direction, referenced to particular wheel profiles.

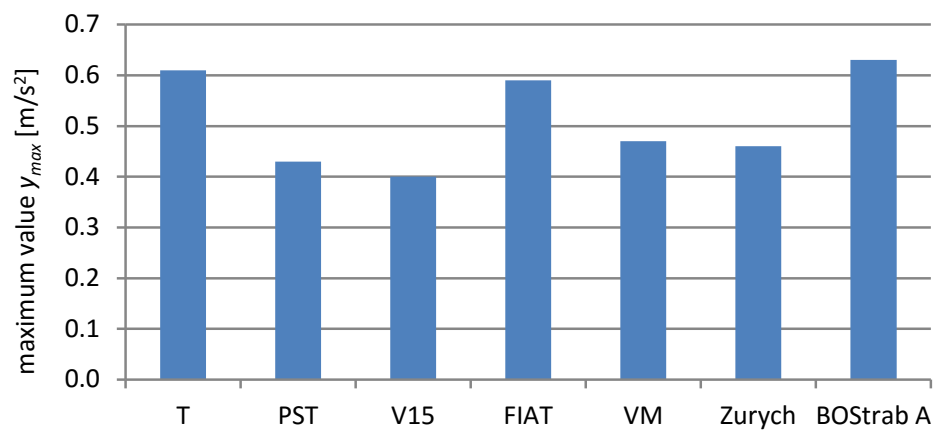

Figure 5: Maximum values of ride index (first car body, lateral direction). 
It appeared that wheel profile geometry has influence on ride index only in lateral direction. Differences were clearly visible. The highest values (the worst ride index) achieved profiles T, FIAT and BOStrab A. V15 and PST reached the lowest values. Ride comfort is a suchlike parameter to ride index, but it takes into consideration vibration acceleration in all directions regarding human perception [8]. The results of comfort $N_{M V}$ calculations are shown in Figure 6.

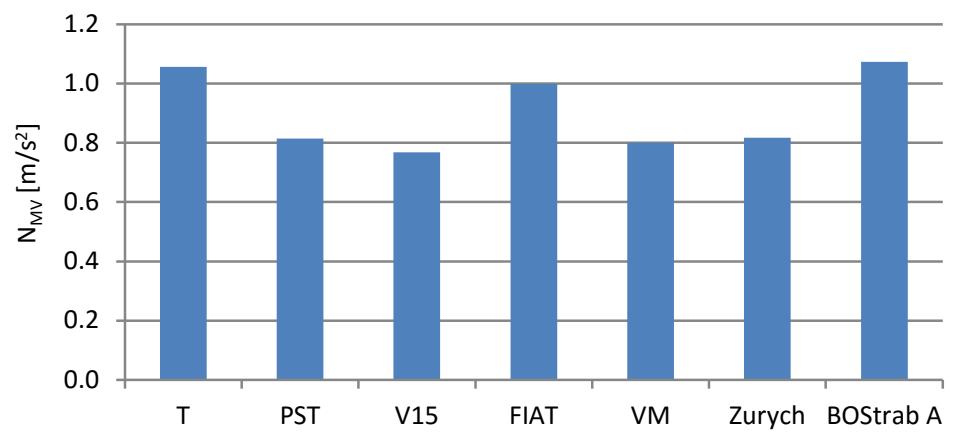

Figure 6: Ride comfort (first car body, lateral direction).

As for previously analysed parameters, profiles T, FIAT and BOStrab A reached the most adverse values. The other profiles achieved similar results. It needs to be mentioned that all profiles' results comprised in the highest comfort level of normative scale [8], hence profile geometry has some influence on ride comfort, but with high probability it will be barely noticed by the passengers.

The number of contact patches is important in terms of wear. Mean value of contact patches number was checked for selected wheel profiles (Figure 7).

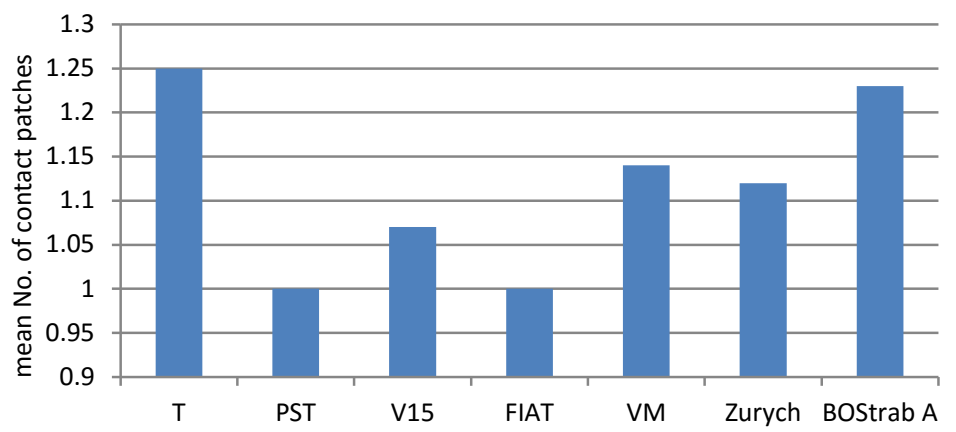

Figure 7: Number of contact patches (first wheelset, right wheel).

Profiles $\mathrm{T}$ and BOStrab A had the highest average number of contact patches, which means that share of multiple-point contact was the biggest. Interesting results were obtained for profiles PST and FIAT. It appears that single-point contact was maintained throughout entire simulation ride. 
From the foregoing it follows that the results were strongly influenced by the wheel/rail clearance. Values of this parameter (in association with 60R2 and 49E1 rails) and flange root radius for particular wheel profiles were presented in Table 2.

Table 2: Wheel/rail clearance and flange root radius for particular wheel profiles.

\begin{tabular}{|l|c|c|c|c|c|c|c|}
\hline Profile & T & PST & V15 & FIAT & VM & Zurich & BOStrab A \\
\hline Clearance $(\mathrm{mm})$ & $\mathbf{2 . 5}$ & 5.0 & 6.3 & $\mathbf{3 . 2}$ & 5.2 & 5.2 & $\mathbf{3 . 0}$ \\
Flange root radius $(\mathrm{mm})$ & 8 & 13 & 13.5 & 15 & 7 & 12 & 12 \\
\hline
\end{tabular}

Wheel profiles formed two groups according to wheel/rail clearance - over $5 \mathrm{~mm}$ and less. Bolded wheel profiles are ones with the lowest values. The same group achieved the worst results in the dynamic analysis, hence it brings out strong influence of wheel/rail clearance on ride characteristics. However, profile FIAT reached one of the best scores regarding mean number of contact patches. The reason is that the radius of transition curve (flange root) between wheel tread and flange is much bigger than corresponding curve radius on rail head geometry. Table 2 supplements Figure 7 with information explaining distribution of the results. It is clearly visible that mean number of contact points (patches) is affected by flange root radius. Profiles with narrower flange roots had higher share of multi-point contact. An important value of flange root radius is $13 \mathrm{~mm}$, because the same radius occurs on corresponding curve of rail head (gauge corner). This is the lowest admissible value for the rail head to fit into wheel's flange root and form single-point contact. But it is not a sufficient condition to make it possible. For example, enlarging the radius of flange root of profile $\mathrm{T}$ to $15 \mathrm{~mm}$ does not prevent from forming two-point contact. It depends also from the rest of profile's geometry nearby the flange.

The influence of wheel/rail clearance modification was investigated for PST profile (Figure 8).

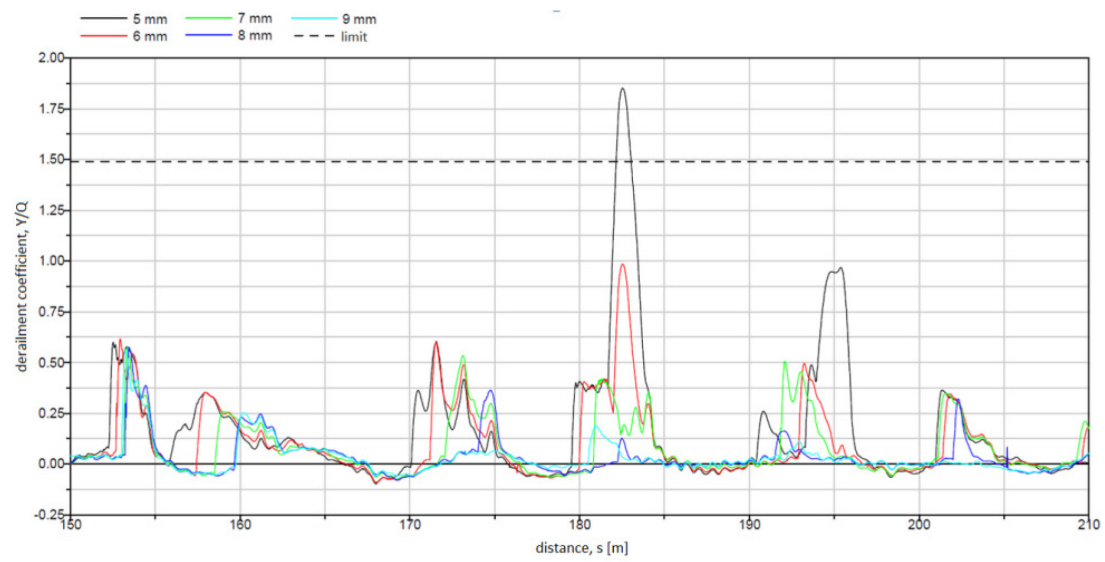

Figure 8: $\quad Y / Q$ coefficient for variable wheel/rail clearance. 
It appears that increasing the clearance to $6 \mathrm{~mm}$ is clearly desired regarding ride safety (no transgressions of $Y / Q$ limiting value). Further growth continues to decrease the derailment coefficient. This trend remains up to $8 \mathrm{~mm}$ clearance. Additional increase leads to very little improvement in ride safety or even its deterioration.

\subsection{Wheel/rail stress analysis}

This section discusses some preliminary results of wheel/rail stress analysis. Figure 9 presents contact stress for PST profile on 60R2 rail (on straight track). Color change towards red means higher stress values.
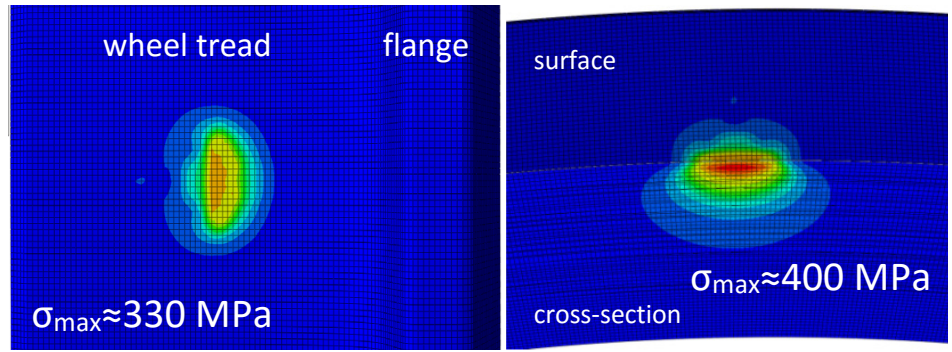

Figure 9: Contact stress on wheel (ride through straight track).

The resultant stress magnitude was far below wheel material's yield point (ca. $740 \mathrm{MPa}$ ) and the top value was localized on some depth under the surface. The shape of contact patch was close to elliptic. Worse results were obtained for some older wheel and rail profiles which are currently being withdrawn from exploitation. Due to low conformity of shapes the contact area was smaller and in consequence - contact stress magnitude was much higher. It is important to mention about the rolling contact fatigue phenomenon (RCF), which causes wheel failures (e.g. cracks) for stress amplitudes much below the yield point. Due to the Wöhler curve for stress magnitudes below some level - the limit of load cycles tends to infinity [9]. Hence, there is another reason for trying to lower the contact stress value between wheel and rail. It is more likely to do regarding tramways than railway vehicles due to lower permissible axle loads (max. $10 \mathrm{t}$ in Poland).

The authors came up with a hypothesis that wider flange tip of wheel contributes to reducing contact stress while riding through flat grooved rail crossings. Profile T has $2.5 \mathrm{~mm}$ wider flange than PST profile. It appeared that regardless of flange tip width contact stress in the interface remained almost the same for equal load conditions and nominal geometry (Figure 10). Form further preliminary analyses it follows that changing the shape of flange tip (rounding it) may effect in decrease of contact stress.

Top stress values were found on flange tip edges and they were close to wheel material's yield point, thus rounding the flange tip may contribute to distributing the stress more evenly along the contact area. This is the reason of accelerated degradation of tram wheels on this part of urban rail infrastructure and an argument 

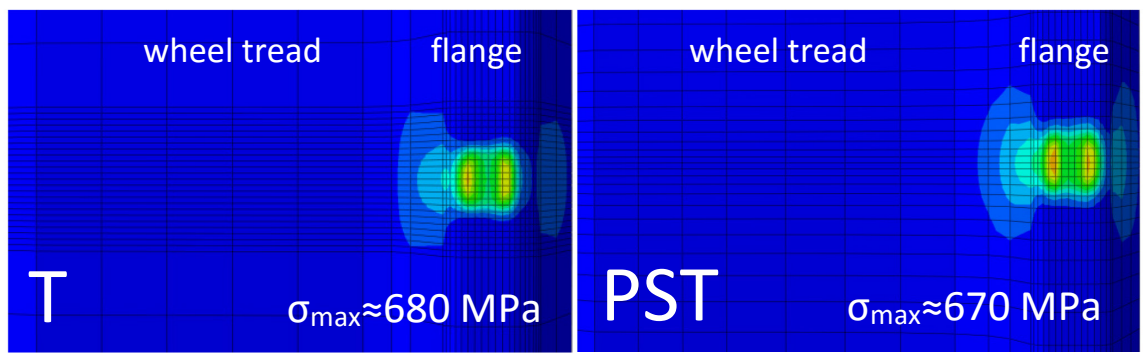

Figure 10: Contact stress on wheel (ride through rail crossing).

for introducing deep grooved rail crossings wherever it is possible (contact stress on wheel tread is much lower). It is worth to mention that above results are effect of static analysis of the phenomenon. Should the analysis be extended to dynamics approach, results will be different, probably higher.

\section{Conclusion}

The performed study was aimed on identifying the phenomena at the tram wheel/rail interface and further - finding fast and accurate enough tools to assess the quality of particular wheel profiles regarding dynamic behaviour and contact mechanics during the optimisation process.

The most influential parameter, regarding ride characteristics is wheel/rail clearance. Its small magnitudes caused deterioration of tramway's dynamic behaviour with respect to $Y / Q$ coefficient, ride index and ride comfort. On the other hand, the radius of flange root and geometry of wheel tread have significant influence on forming contact points. The flange root shape should enable the rail's gauge corner to fit in and set up single-point contact. Multiple-point contact has negative influence on wear intensity and dynamics behaviour.

Lowering the contact stress magnitude below the material's yield point do not exclude the possibility of rolling contact fatigue related failures. Due to specific distribution of contact stress on wheel flange while riding through flat grooved rail crossings, flange width parameter had no impact on the stress magnitudes. While modification of its shape by rounding it may cause decrease of contact stress.

\section{Acknowledgement}

All presented work is realized within the framework of a research project "Identification and modelling of nonlinear phenomena at the wheel/rail contact area for the development of a new tramway wheel profile" (LIDER/20/521/L$4 / 12 / \mathrm{NCBR} / 2013)$, that has been started with a financial support from the Polish National Centre for Research and Development. 
440 Computers in Railways XV: Railway Engineering Design and Operation

\section{References}

[1] Andersson, E., Berg, M. \& Stichel, S. Rail Vehicle Dynamics, Railway Group KTH, Stockholm, 2014.

[2] Markine, V. L., Shevtsov, I. Y. \& Esveld, C. An inverse shape design method for railway wheel profiles, Structural and Multidisciplinary Optimization Vol. 33, 2007.

[3] Braghin, F., Bruni, S. \& Lewis, R. Railway wheel wear, in: Wheel/rail interface handbook, Lewis, R. \& Olofsson, U. (eds.), Woodhead Publishing, Cambridge, 2011.

[4] Grassie, S. L. Maintenance of the wheel/rail interface, in: Wheel/rail interface handbook, Lewis, R. \& Olofsson, U. (eds.), Woodhead Publishing, Cambridge, 2011.

[5] Iwnicki, S., Björklund, S. \& Enblom, R. Wheel-rail contact mechanics in: Wheel/rail interface handbook, Lewis, R. \& Olofsson, U. (eds.), Woodhead Publishing, Cambridge, 2011.

[6] Firlik, B., Czechyra, B. \& Sawczuk, W. Identification and Modeling of Nonlinear Phenomena at the Wheel/Rail Contact Area, in: Proceedings of the Second International Conference on Railway Technology: Research, Development and Maintenance, Pombo J. (ed.), Civil-Comp Press, Stirlingshire, 2014.

[7] EN 14363. Railway applications - Testing for the acceptance of running characteristics of railway vehicles - Testing of running behavior and stationary tests.

[8] EN 12299. Railway applications - Ride comfort for passengers Measurement and evaluation.

[9] Ekberg, A. Fatigue of railway wheels, in: Wheel/rail interface handbook, Lewis, R. \& Olofsson, U. (eds.), Woodhead Publishing, Cambridge, 2011. 